Supplement of Weather Clim. Dynam., 1, 405-426, 2020

https://doi.org/10.5194/wcd-1-405-2020-supplement

Weather and

(C) Author(s) 2020. This work is distributed under

the Creative Commons Attribution 4.0 License.

(c) (1)

Supplement of

\title{
The sensitivity of atmospheric blocking to upstream latent heating - numerical experiments
}

Daniel Steinfeld et al.

Correspondence to: Daniel Steinfeld (daniel.steinfeld@alumni.ethz.ch)

The copyright of individual parts of the supplement might differ from the CC BY 4.0 License. 


\section{Synoptic overview for cases Canada, Cold spell and Russia}

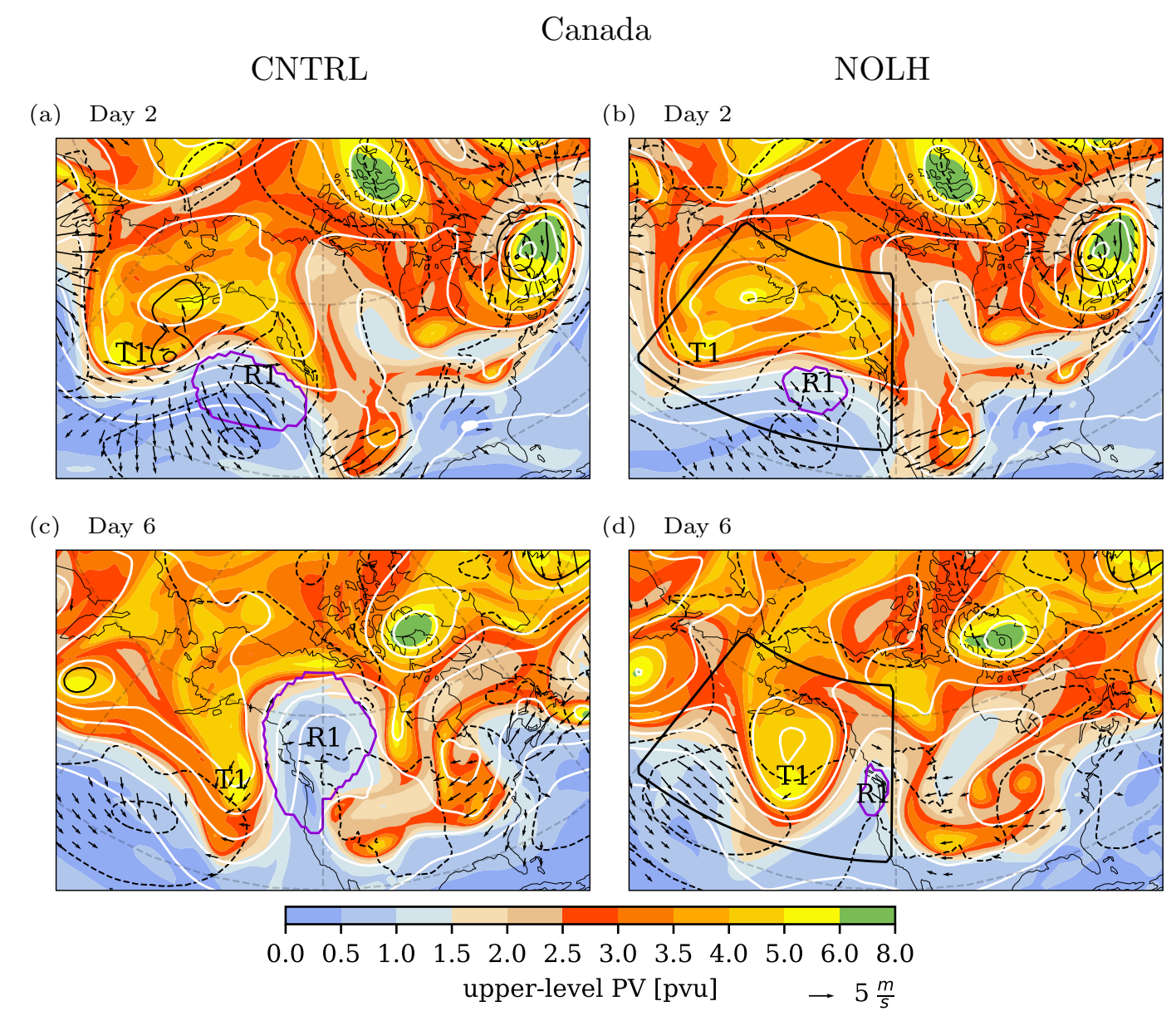

Figure S1. Upper-level PV (in pvu, shaded), upper-level divergent wind (black vectors according to reference vector, only shown for wind speed larger than $2 \mathrm{~m} \mathrm{~s}^{-1}$ ), geopotential height at $500 \mathrm{hPa}$ (white contours every $100 \mathrm{gpm}$ ), SLP (solid black contours from $1000 \mathrm{hPa}$ every $-10 \mathrm{hPa}$, dashed contours from $1020 \mathrm{hPa}$ every $+10 \mathrm{hPa}$ ), and blocking region (magenta contour for PV anomaly of $-1 \mathrm{pvu}$ ) in (left) CNTRL and (right) NOLH simulation at (a,b) 18 UTC 29 April 2016 (day 2) and (c,d) 15 UTC 2 May 2016 (day 6). Labels "T1" and "R1" mark troughs and ridges. Black box in NOLH indicates region where LH is turned off. 


\section{CNTRL}

(a) Day 2

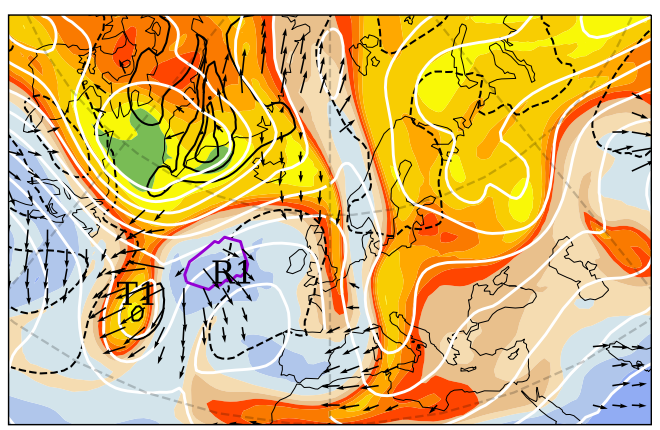

(c) Day 6

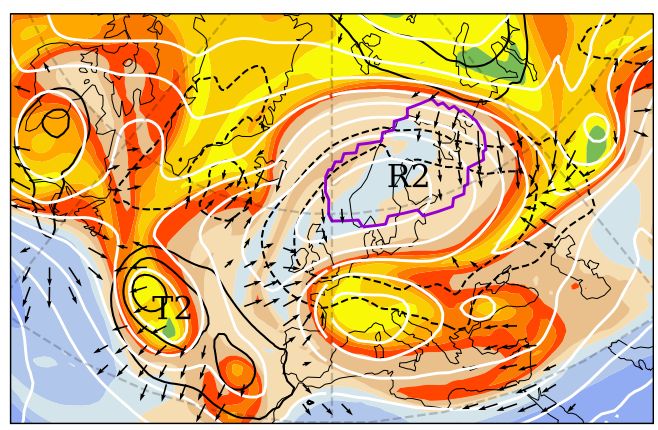

(d) Day 6

\section{NOLH}

(b) Day 2
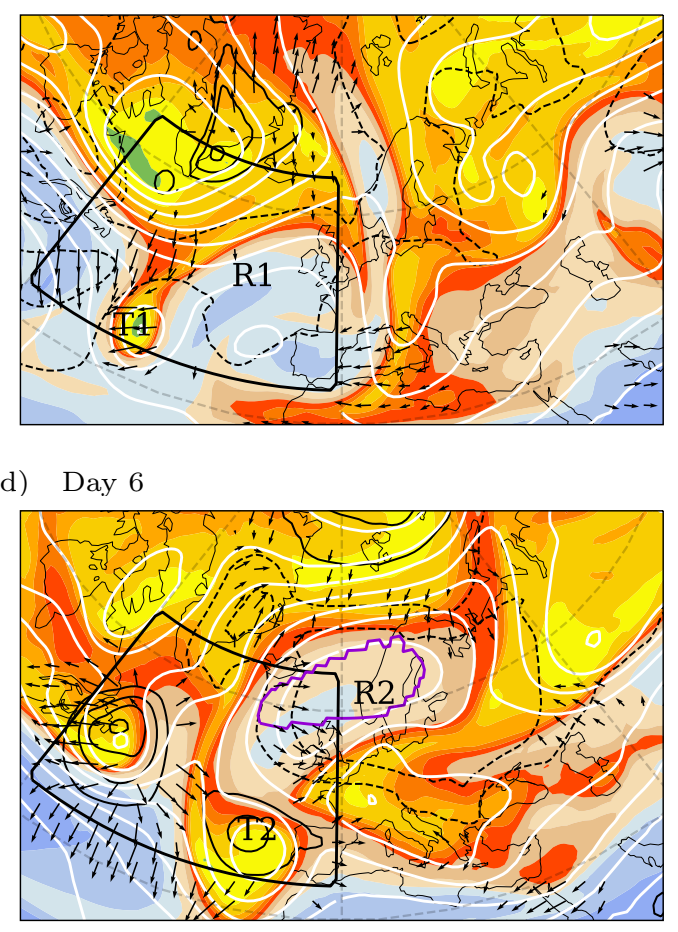

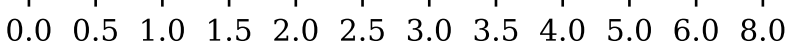

upper-level PV [pvu] $\rightarrow 5 \frac{\mathrm{m}}{\mathrm{s}}$

Figure S2. Upper-level PV (in pvu, shaded), upper-level divergent wind (black vectors according to reference vector, only shown for wind speed larger than $2 \mathrm{~m} \mathrm{~s}^{-1}$ ), geopotential height at $500 \mathrm{hPa}$ (white contours every $100 \mathrm{gpm}$ ), SLP (solid black contours from $1000 \mathrm{hPa}$ every $-10 \mathrm{hPa}$, dashed contours from $1020 \mathrm{hPa}$ every $+10 \mathrm{hPa}$ ), and blocking region (magenta contour for PV anomaly of $-1 \mathrm{pvu}$ ) in (left) CNTRL and (right) NOLH simulation at (a,b) 15 UTC 20 February 2018 (day 2) and (c,d) 21 UTC 24 February 2018 (day 6). Labels "T1,T2" and "R1,R2" mark troughs and ridges. Black box in NOLH indicates region where LH is turned off. 


\section{CNTRL \\ Russia \\ $\mathrm{NOLH}$}

(a) Day 2

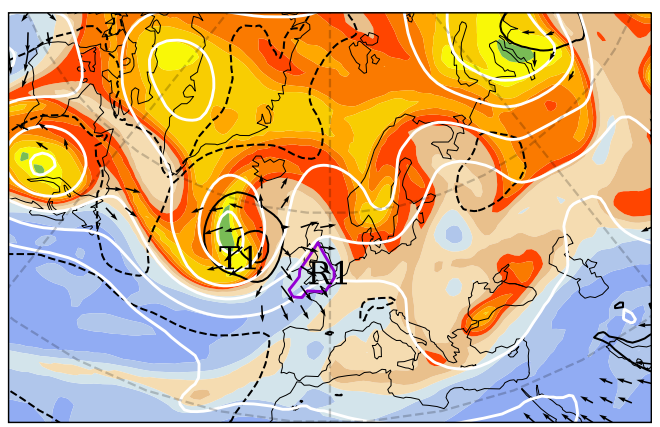

(c) Day 6

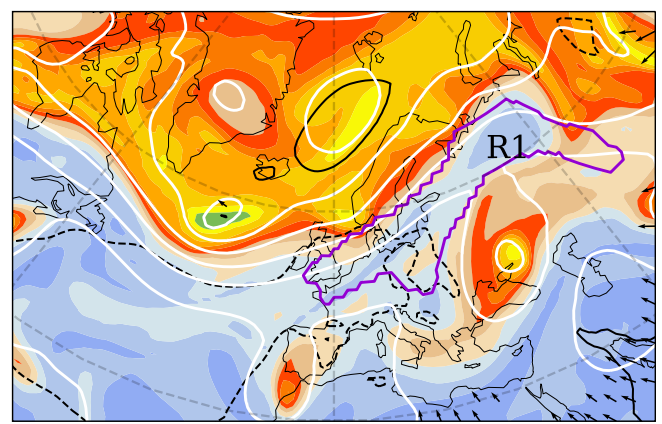

(b) Day 2

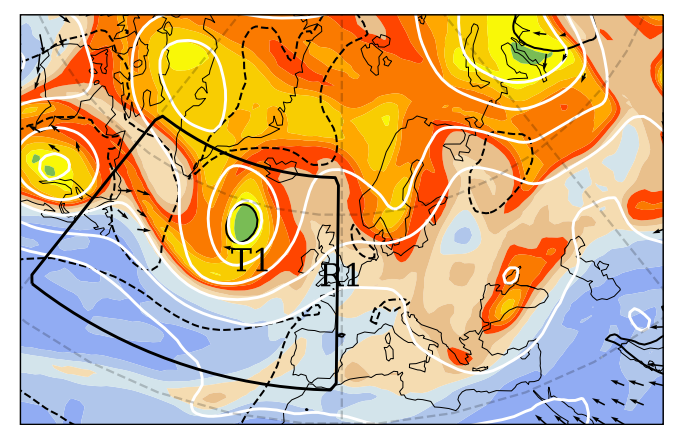

(d) Day 6

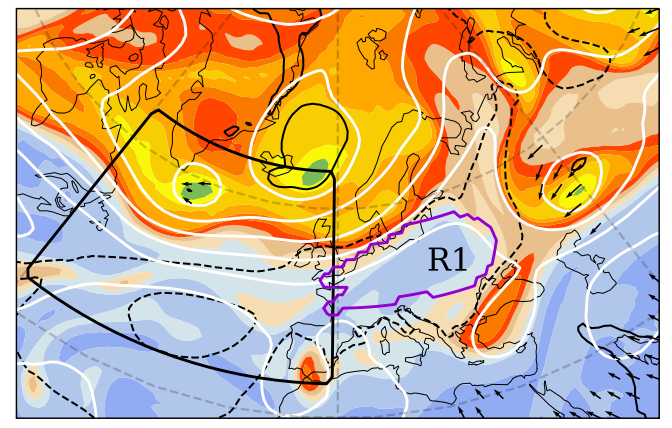

$\begin{array}{lllllllllllll}0.0 & 0.5 & 1.0 & 1.5 & 2.0 & 2.5 & 3.0 & 3.5 & 4.0 & 5.0 & 6.0 & 8.0\end{array}$

upper-level PV [pvu] $\rightarrow 5 \frac{\mathrm{m}}{\mathrm{s}}$

Figure S3. Upper-level PV (in pvu, shaded), upper-level divergent wind (black vectors according to reference vector, only shown for wind speed larger than $2 \mathrm{~m} \mathrm{~s}^{-1}$ ), geopotential height at $500 \mathrm{hPa}$ (white contours every $100 \mathrm{gpm}$ ), SLP (solid black contours from $1000 \mathrm{hPa}$ every $-10 \mathrm{hPa}$, dashed contours from $1020 \mathrm{hPa}$ every $+10 \mathrm{hPa}$ ), and blocking region (magenta contour for PV anomaly of $-1 \mathrm{pvu}$ ) in (left) CNTRL and (right) NOLH simulation at (a,b) 21 UTC 30 June 2010 (day 2) and (c,d) 00 UTC 5 July 2010 (day 6). Labels "T1" and "R1" mark troughs and ridges. Black box in NOLH indicates region where LH is turned off. 


\section{Synoptic comparison between CNTRL and ERA-Interim}

The following Figure S4 compares upper-level PV between the control simulation (CNTRL) and ERA-Interim (ERA-I, Dee et al., 2011) for the cases Thor onset, Thor maintenance, Canada, Cold spell and Russia. After 3 days of model simulation 5 (left panels in Fig. S4), the initial ridge amplification is very well represented in all cases with only minor differences in the upper-level PV compared to ERA-I. 6 days into the model simulation during the mature phase (middle panels in Fig. S4), the intensity and spatial extent of the mature block are generally well represented in the CNTRL simulations. However, positive and negative upper-level PV differences between CNTRL and ERA-I are found near the flanks of the blocking anticyclones, indicating a shift in location of the negative PV anomalies. 10 days into the model simulation (right panels in Fig. S4), both the CNTRL simulations and ERA-I show the decay phase of the blocks, but up- and downstream ridges and troughs are strongly displaced with marked differences in the upper-level PV pattern. Nevertheless, the forecast evolution of the blocks in the CNTRL simulations is similar enough to ERA-I over the time of interest (onset and mature phases) and captures an intense blocking anticyclone. It thus allows studying the impact of LH on the flow amplification in the IFS sensitivity experiments. 
(a)

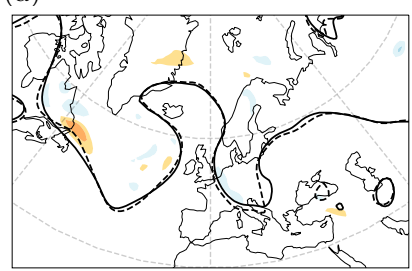

(d)

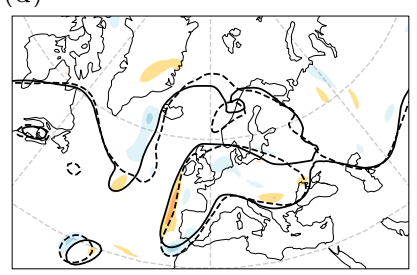

(g)

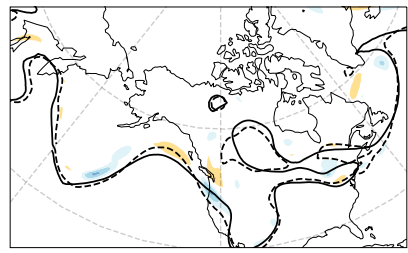

(j)

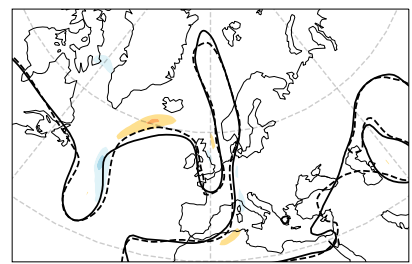

(m)

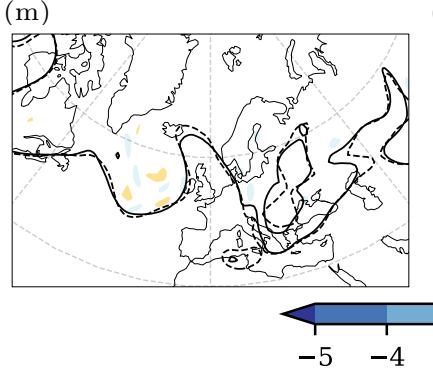

(b)

Thor onset

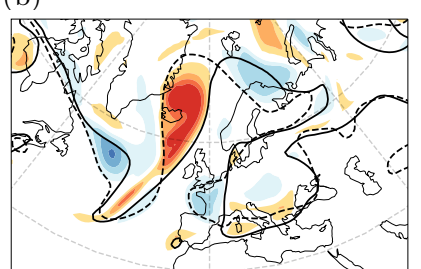

Thor maintenance

(e)

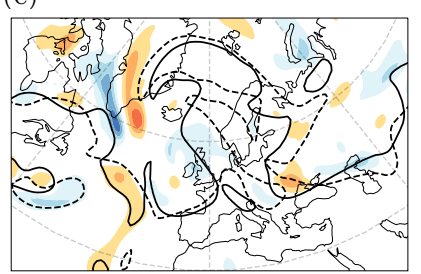

Canada

(h)

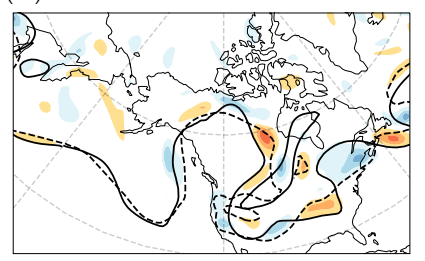

Cold spell

(k)

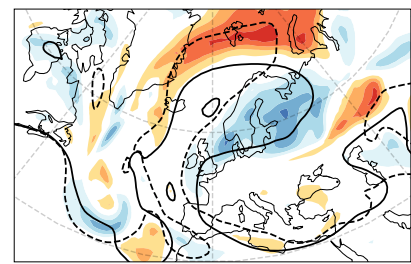

Russia

(n)

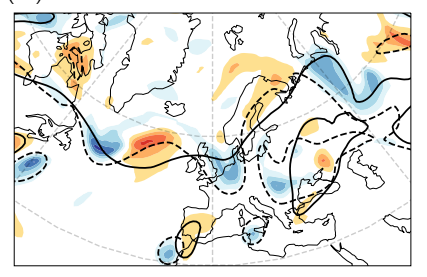

(1)

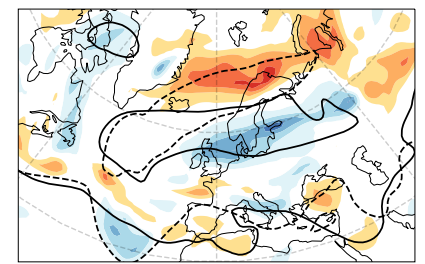

(c)

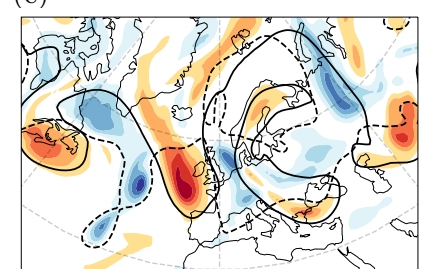

(f)

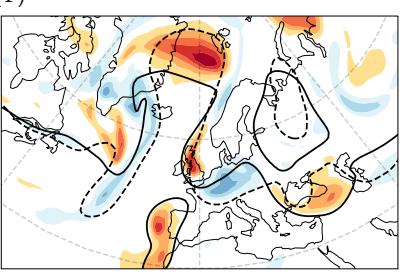

(i)

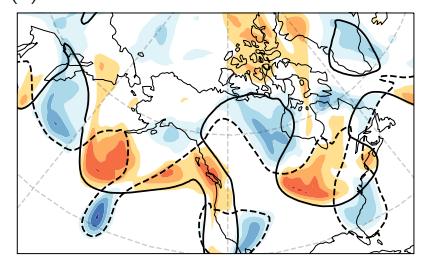

(o)

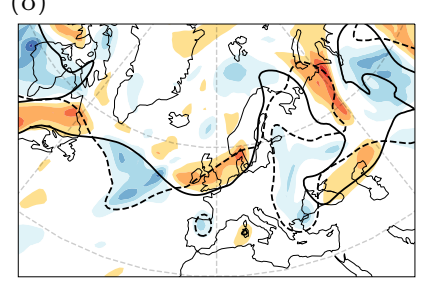

Figure S4. Difference (CNTRL - ERA-I) in upper-level PV (shaded in pvu) and upper-level 2 pvu contour (solid for CNTRL, dashed for ERA-I) after (left panels) 3 days, (middle panels) 6 days and (right panels) 10 days of model simulation. 


\section{References}

15 Dee, D. P., Uppala, S. M., Simmons, A. J., Berrisford, P., Poli, P., Kobayashi, S., Andrae, U., Balmaseda, M. A., Balsamo, G., Bauer, P., Bechtold, P., Beljaars, A. C. M., van de Berg, L., Bidlot, J., Bormann, N., Delsol, C., Dragani, R., Fuentes, M., Geer, A. J., Haimberger, L., Healy, S. B., Hersbach, H., Hólm, E. V., Isaksen, L., Kållberg, P., Köhler, M., Matricardi, M., Mcnally, A. P., Monge-Sanz, B. M., Morcrette, J. J., Park, B. K., Peubey, C., de Rosnay, P., Tavolato, C., Thépaut, J. N., and Vitart, F.: The ERA-Interim reanalysis: configuration and performance of the data assimilation system, Q. J. R. Meteorol. Soc., 137, 553-597, https://doi.org/10.1002/qj.828, 2011. 